\title{
Research Paper: Investigation of the Effictiveness of Group Play Therapy Training With Cognitive-Behavioral Approach on the Social Skills of Students With Intellectual Disability
}

\author{
${ }^{*}$ Mohammad Ashori ${ }^{1}$ (D), Masoume Yazdanipour ${ }^{1}$
}

1. Department of Psychology and Education of Children With Special Needs, Faculty of Education and Psychology, University of Isfahan, Isfahan, Iran.

\begin{tabular}{|c|c|}
\hline $\begin{array}{l}\text { Use your device to scan } \\
\text { and read the article online }\end{array}$ & Crtation Ashori M, Yazdanipour M. [Investigation of the Effictiveness of Group Play Therapy Training With Cognitive- \\
\hline 口:15 & $\begin{array}{l}\text { Behavioral Approach on the Social Skills of Students With Intellectual Disability (Persian)]. Archives of Rehabilitation. 2018; } \\
\text { 19(3):262-275. http://dx.doi.org/10.32598/rj.19.3.262 }\end{array}$ \\
\hline 口iftis & dol: $:$ http://dx.doi.org/10.32598/rj.19.3.262 \\
\hline
\end{tabular}

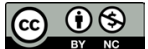

Funding: See Page 272

Received: 17 Apr 2018 Accepted: 20 Aug 2018 Available Online: 01 Oct 2018

\section{A B STRACT}

Objective Intellectual disability is a common neurodevelopmental disorder which leads to lower social activities, skills and life quality. It seems that play therapy could improve social skills of students with intellectual disability. Play is one of the important methods for social skills training to students with intellectual disability. Group play therapy enhances social skills like leadership among children. Cognitive-behavioral play therapy has been proposed since several decades ago as an intervention program for developing social relationships and skills in children with intellectual disability. Cognitive-Behavioral Play Therapy (CBPT) is a developmentally sensitive adaptation of cognitivebehavioral therapy. In CBPT, play is a medium to communicate and indirectly teach empiricallysupported techniques to children in an engaging way. So, it is important to plan suitable training programs such as group play therapy training program for improving social skills of children with intellectual disability. The purpose of the present study was to investigate of the efficacy of group play therapy training with cognitive-behavioral approach on the social skills of students with intellectual disability in Isfahan City, Iran.

Materials \& Methods The present research was a quasi-experimental study with pretest, post-test design and control group. The participants were 22 students with intellectual disability aged 7-11 years in 2017-2018 academic year. They belonged to middle socio-economical class. Subjects were selected by convenience sampling method from school of Shahidan Nouri in Isfahan. They were divided into experimental and control groups, each group consisting of 14 students. The experimental group received group play therapy training program in 7 sessions (each session 40 minutes), while control group did not participate in this program but participated in common group play therapy program in the school. The study instrument was the social skills scale of Matson. Social skills scale was completed by parents for all subjects in pretest and post-test. The relevant data were collected through the questionnaire before and after the training sessions. Multivariate Analysis of Covariance (MANCOVA) was performed in SPSS V. 23.

Results first, normality of variables and contingency of variance and covariance assumptions were tested. The Kolmogorov-Smirnov test showed that all variables were normally distributed $(P>0.05)$. Also, Box test confirmed contingency of variance-covariance assumption. So, assumptions of MANCOVA test were confirmed and could be used for data analysis. The results of MANCOVA showed that group play therapy training with cognitive-behavioral approach program had a significant effect on the social skills of students with intellectual disability $(P<0.001)$. The results also revealed

\section{* Corresponding Author: \\ Mohammad Ashori, PhD}

Address: Department of Psychology and Education of Children With Special Needs, Faculty of Education and Psychology, University of Isfahan, Isfahan, Iran. Tel: +98 (31) 37932548

E-Mail: m.ashori@edu.ui.ac.ir 
Keywords: Group play therapy, Social skills, Intellectual disability that group play therapy training program had a significant effect on all subscales of social skills (appropriate social behavior, asocial behavior, aggressive and impulsive behavior, superiority and selfconfidence, communication with peers) in these students ( $\mathrm{P}<0.001)$. It can be stated that according to Eta square, $67 \%, 55 \%, 61 \%, 56 \%, 62 \%$, and $55 \%$ of variations in components of appropriate social behavior, asocial behavior, aggressive and impulsive behavior, superiority and self-confidence, communication with peers, and social skills, respectively, can be explained by the subjects' participation in group play therapy training program.

Conclusion Group play therapy training program with cognitive-behavioral approach improved the social skills of students with intellectual disability. In other words, applying this training program has been associated with effective and positive outcomes, because social skills of the control group did not shown significant improvement. Therefore, paying attention to the group play therapy training program with cognitive-behavioral approach is essential and planning for providing training of this type of group play therapy program for children and students with intellectual disability is of particular importance. 


\title{
بررسى تأثير آموزش بازىدرمانى كَروهى با رويكرد شناختى رفتارى بر مهارتهاى اجتماعى

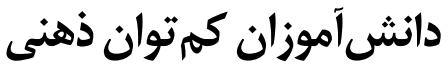

\author{
"محمد عاشورى' (이، معصومه يزدانىيور'
}

1- كروه كود كان با نيازهاى خاص، دانشكده علوم تربيتى و روانشناسى، دانشًاه اصفهان، اصفهان، ايران.

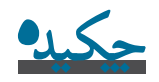

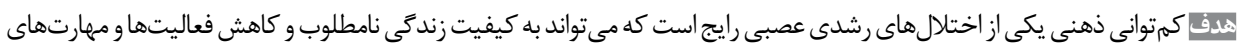

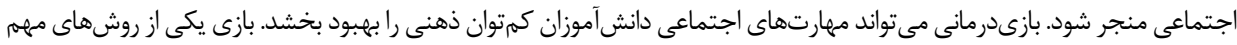

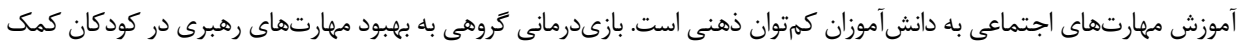

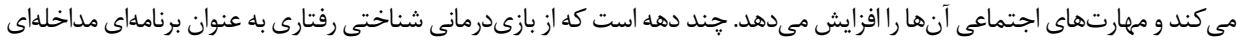

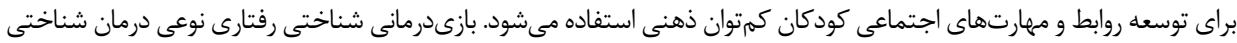

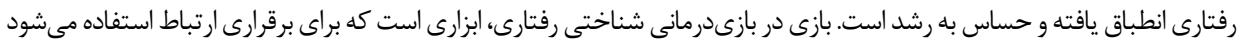

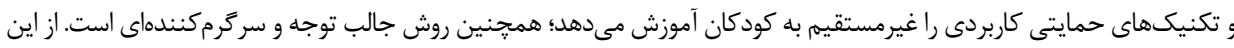

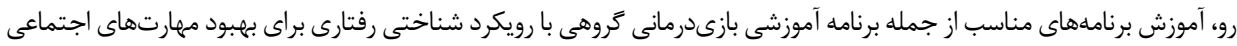

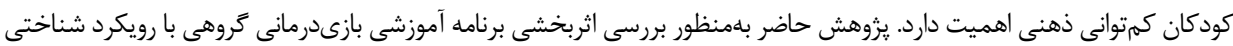

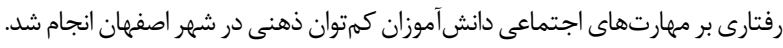

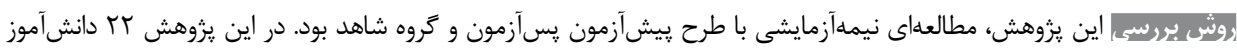

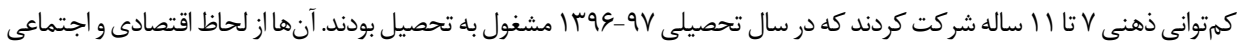

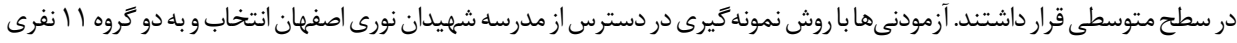

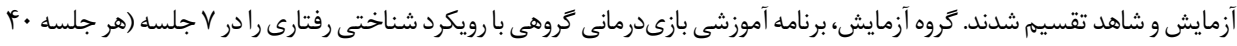

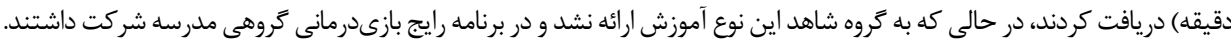

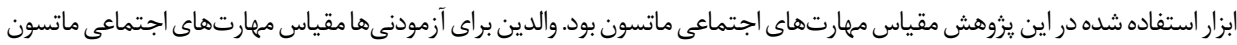

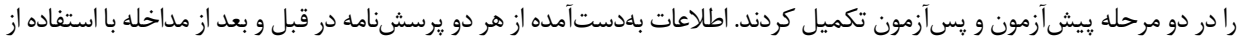

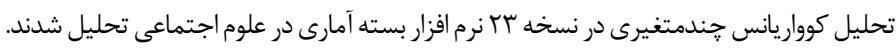

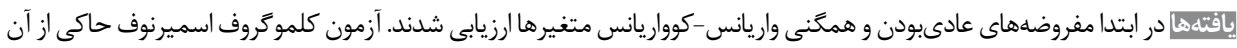

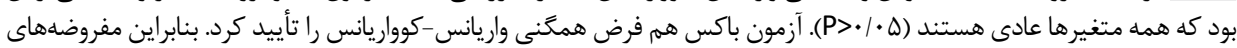

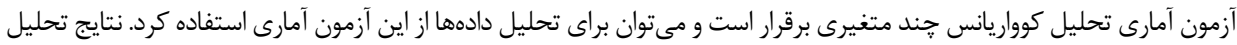

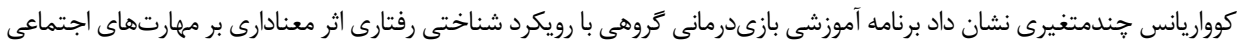

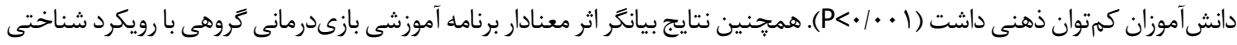

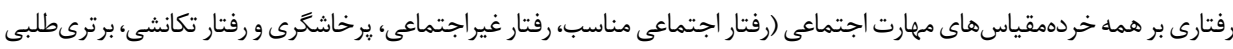

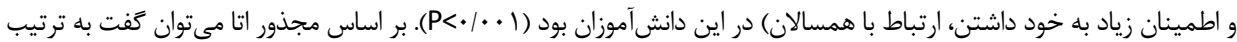

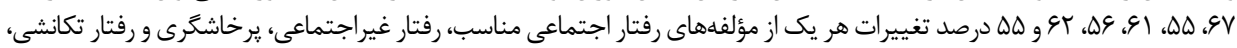

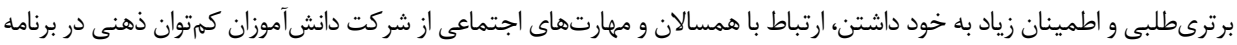

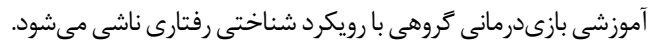

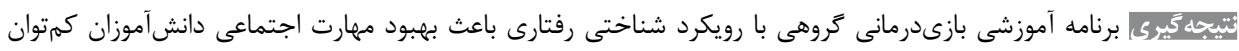

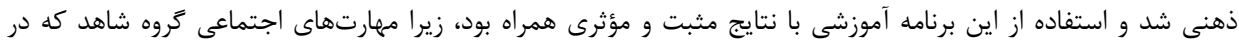

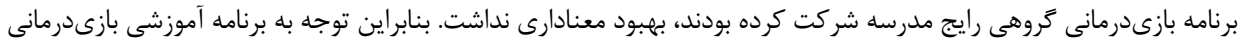

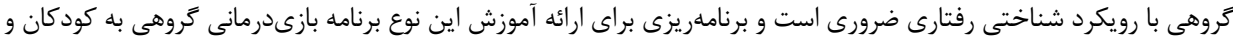

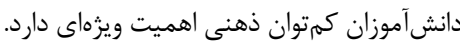

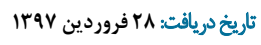

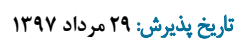 \\ تاريخ انتشار: ا. مهر
}

كليدوأرهها:

بازىدرمانى گروهي، مهارتهاى اجتماعى، كمتوانى ذهنى

도.

نشانى: اصفهان، دانشكاه اصفهان، دانشكده علوم مانى تربيتى و روانشناسى، كروه روانشناسى و آموزش كودكان با نيازهاى خاص. 


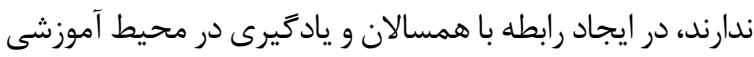

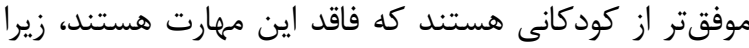

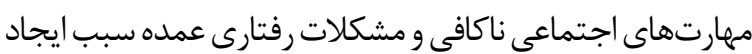

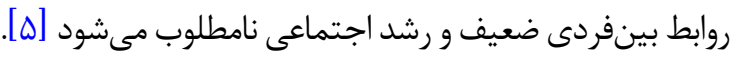

برخى متخصصان اعتقاد دارند ميزان واكنشهاى هيجانى

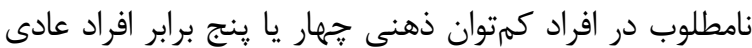

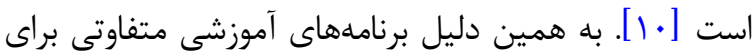

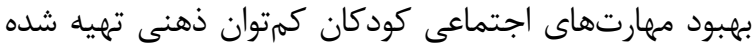

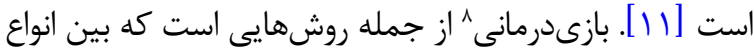

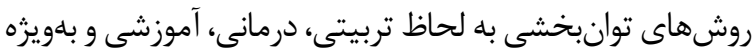

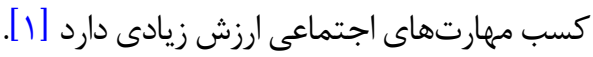

در واقع، بازىدرمانى رويكردى ساختارمند است كه كه

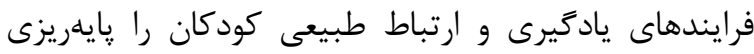

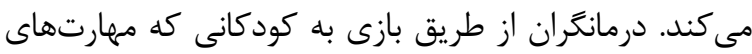

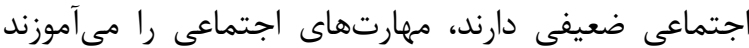

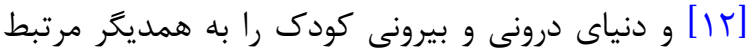

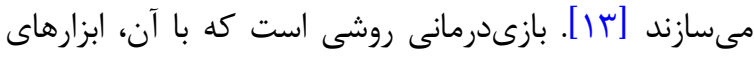

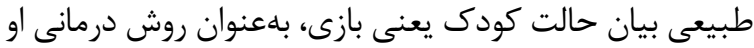

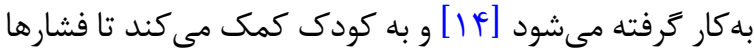

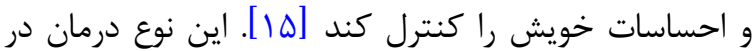

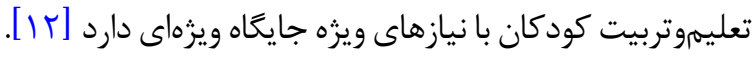
يزوهش هاى مختلفى در حوزه بررسى تأثير آموزش بازى درمانى

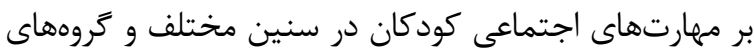

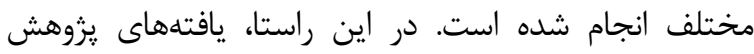

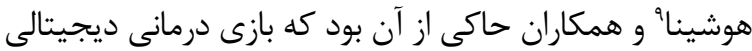

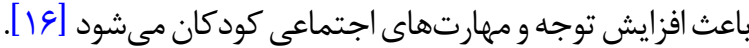

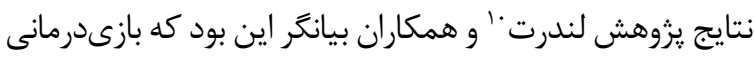

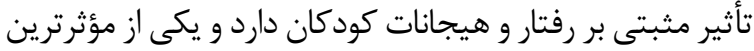

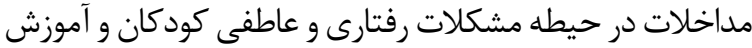

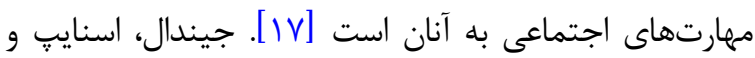

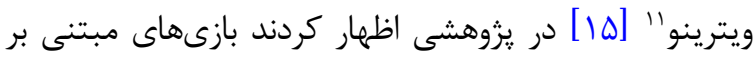

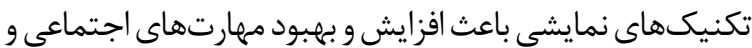

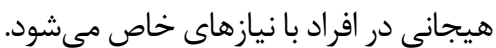

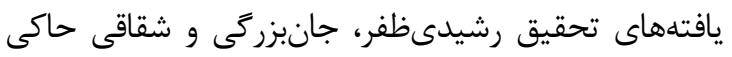

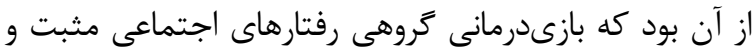

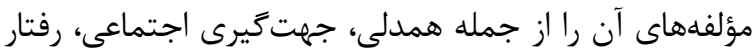

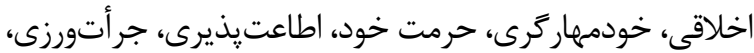

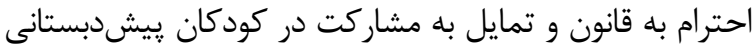

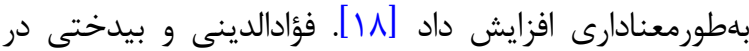

8. Play therapy

9. Hoshina

10. Landreth

11. Lindal, Snape and Vettraino
مقلمه

كمتوانى ذهنى يا ناتوانى هوشى' با شرايطى يكسان و به

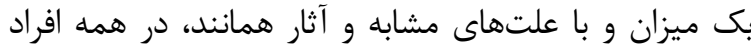

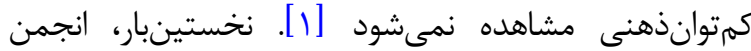

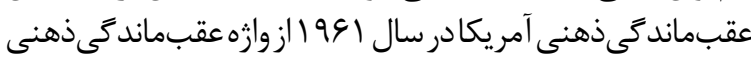

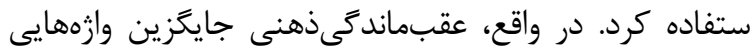

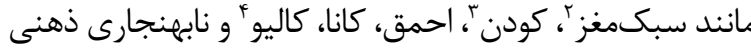

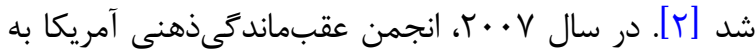

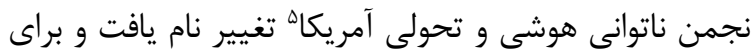

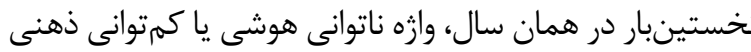

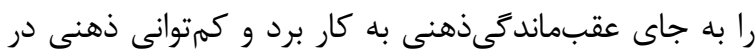

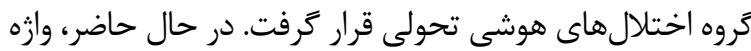

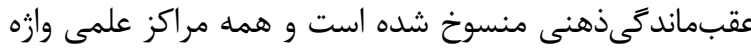
كمتوانى ذهنى را تأييد مى كنند [ب].

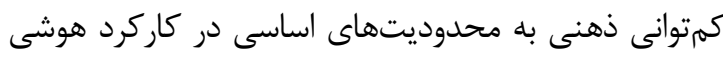

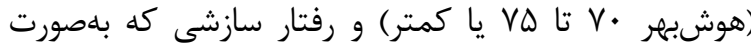

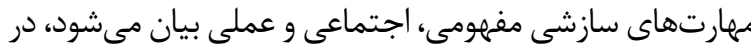

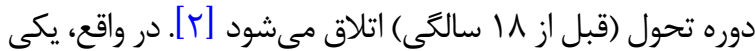

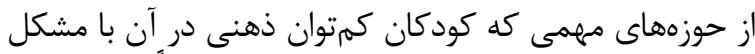

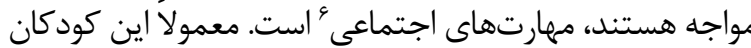

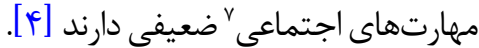

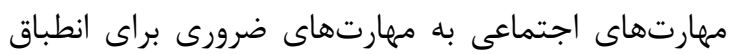

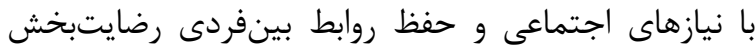

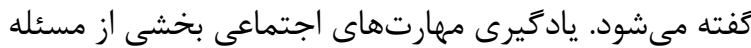

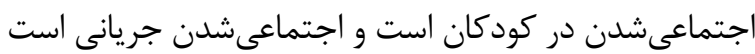

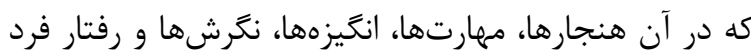

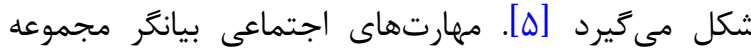

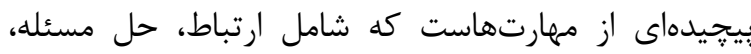

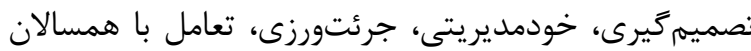

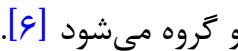
بيشتر كودكان در ارتباط با اطرافيان (والدين، خواهران، برادران

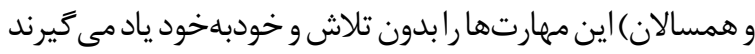

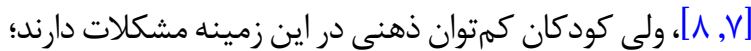

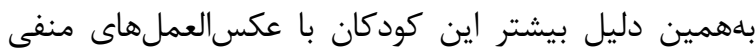

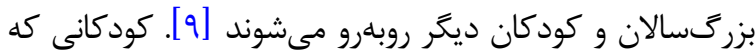
مهارت اجتماعى مطلوبى دارند و مشكلات رفتارى دون عمدهاي

1. Intellectual Disability (ID)

2. Feeblemindedness

3. Moron

4. Imbecile

5. American Association of Intellectual Developmental Disability (AAIDD)

6. Social skills

7. Social skills 


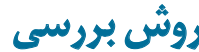

در يزوهش حاضر كه از نوع مطالعات نيمهآزمايشى است، از از

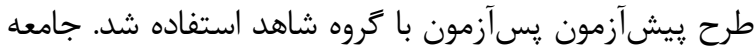

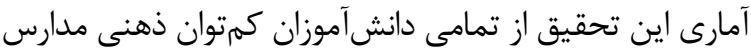

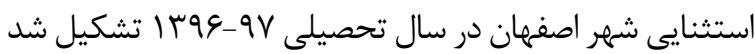

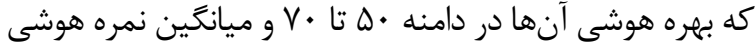

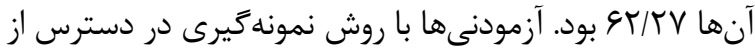

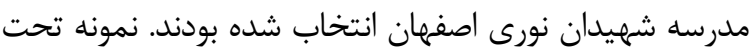

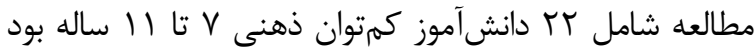

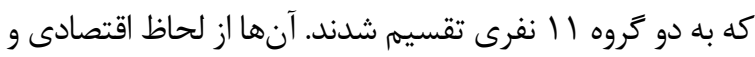
اجتماعى در سطح متوسطى بودند.

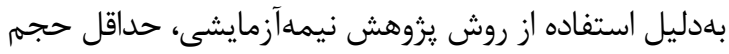

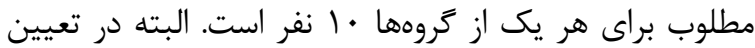

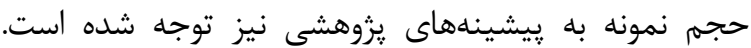

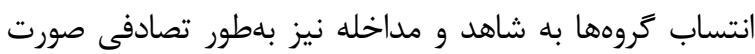

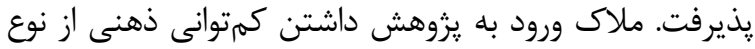

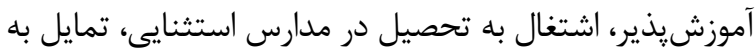

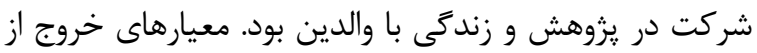

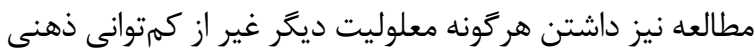

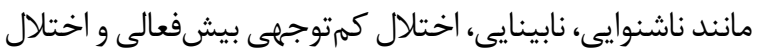

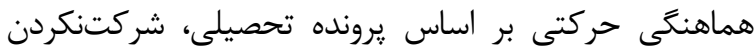

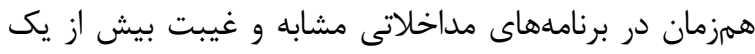

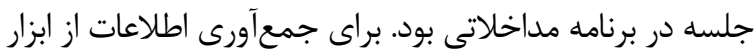

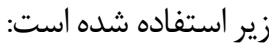

\section{مثياس مهارثهاى اجتماعى ماتسون"}

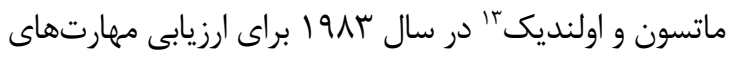

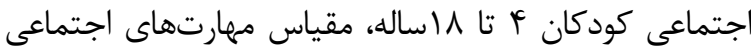

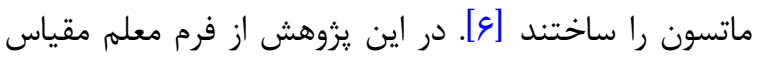

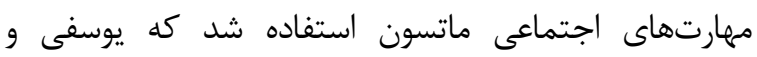

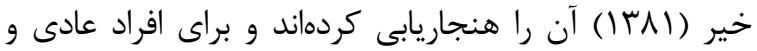

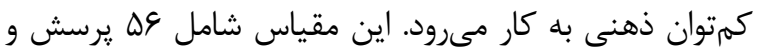

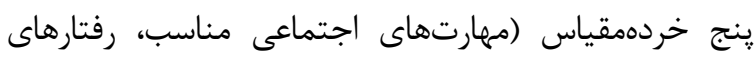

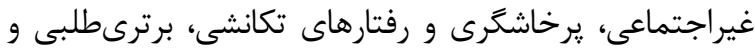

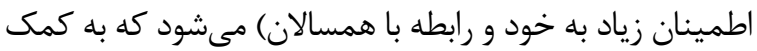

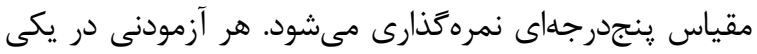

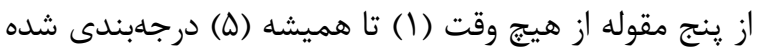

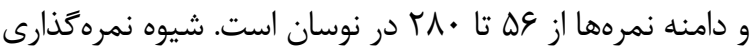

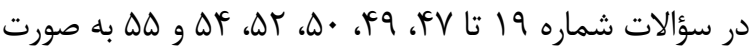

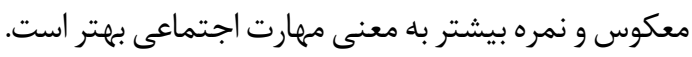

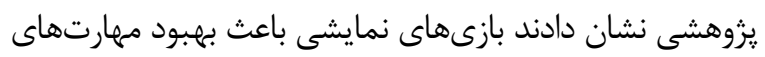

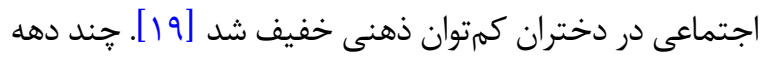

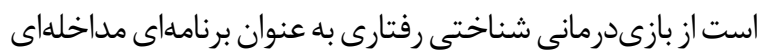

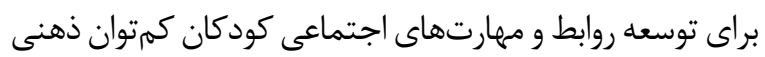

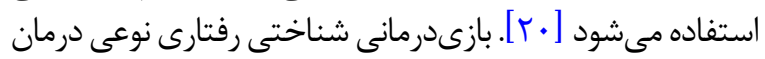

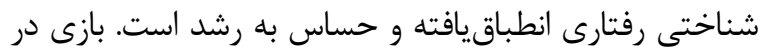

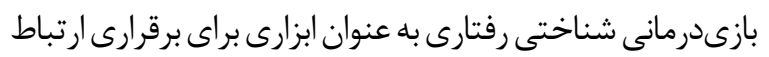

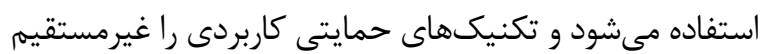

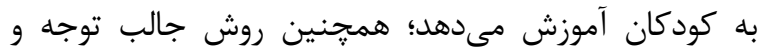

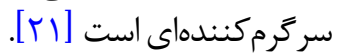

يكى از برجستهترين رويكردهاى بازى در مانى كه براى كود كان

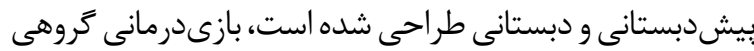

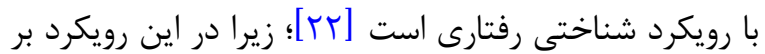

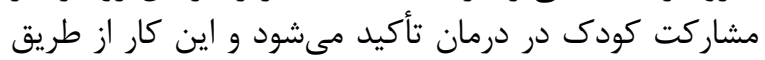

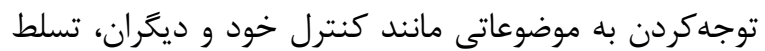

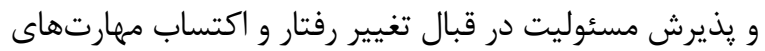

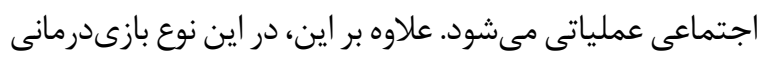

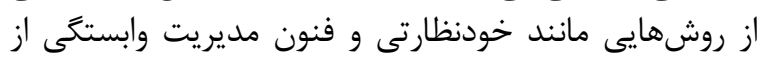

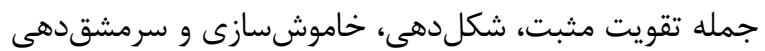

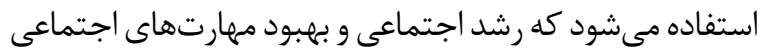

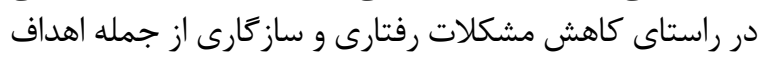

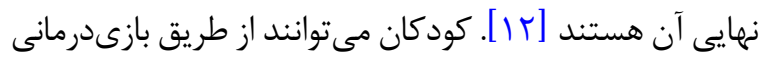

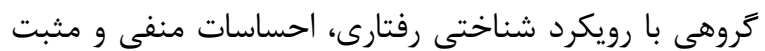

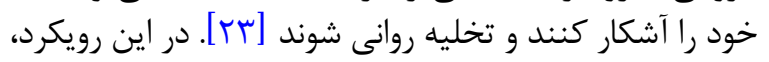

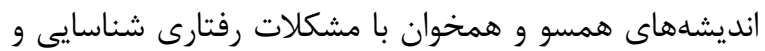

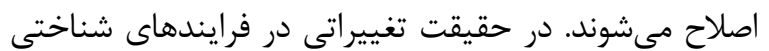

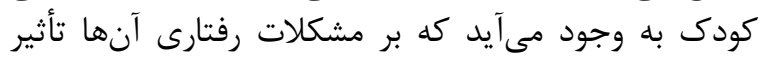

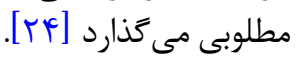

با توجه به اينكه در آموزشويرورش كودكان كمتوان ذهنى،

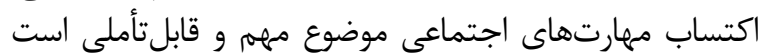

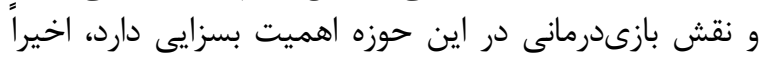

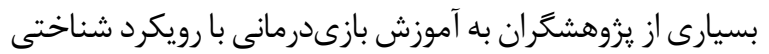

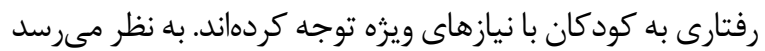

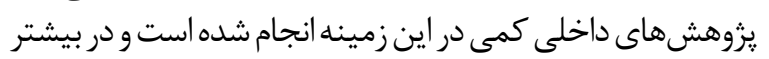

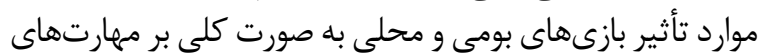

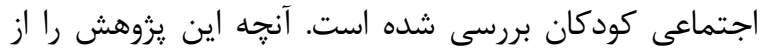

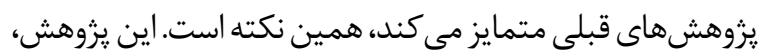

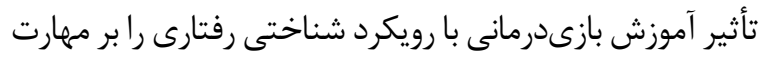

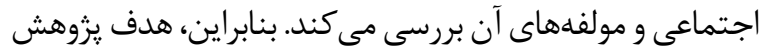

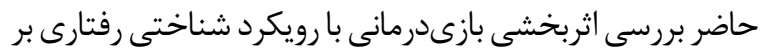

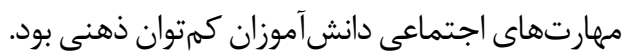


جدول ا. هدف و محتواى جلسات بازىدرمانى گروهى در تروه آزمايش

\begin{tabular}{|c|c|c|}
\hline 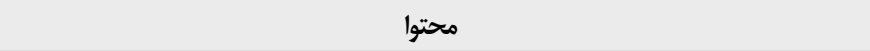 & هدف & 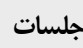 \\
\hline اعلام قوانينى خون رعايت ادب در برخورد با دوستان و همكارى، بازى توب و سطل با شمارش گروهى & 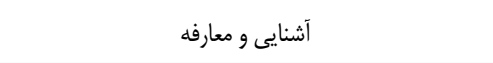 & 1 \\
\hline بازى يانتوميم، بازى با اشكال هندسى بdصورت گروهى & افزايش مهارت خودآكاهى & r \\
\hline نمايش فيله، بازى با نخ و مهره، بازى بولينگ & بهبود مهارت تهاى حركتى و خود كنترلى & r \\
\hline بازى با لوَّو و ساختن تفنت، خانه و ماشين، شهر سازى به صورت كروهى با لوكّو & بهبود مهارت حلمسئله، تصميمَيرى و مشاركت گروهى & r \\
\hline 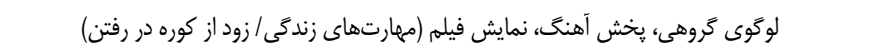 & تقويت همكارى و ابراز هيجان & $\Delta$ \\
\hline بازى با توب، بازى با توب و سطل فيلم (مهارتهاى زندگَى / آداب مهمان نوازى) به همراه كليبٍ (ترانه & آكاهى از نشانهاى رفتار هاى و يادكّيرى ياسخهاى & s \\
\hline بازى وسطى، يخش كليب ترانه نمره •. ا، تقدير از دانشآموزان و نظرخواهى از آنها & تقويت فعاليتهاى مشاركتى و ارتباط بينفردى و كروهى & v \\
\hline
\end{tabular}

توانبخننى

كوواريانس تكمتغيرى و جندمتغيرى تجزيه و تحليل شد. براى تحليل دادهها از نسخه سب نرمافزار آمارى SPSS استفاده شدي.

\section{ياثتهها}

يافتههاى توصيفى بيانكر سن آزمودنىها در كروه آزمايش

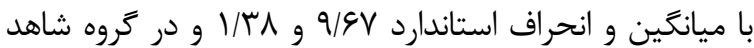

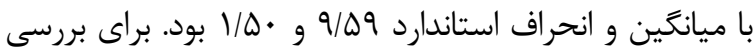

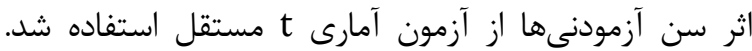

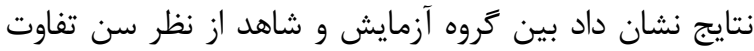

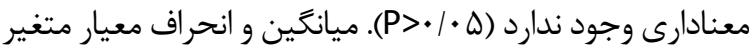

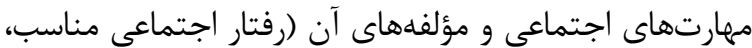

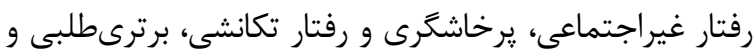

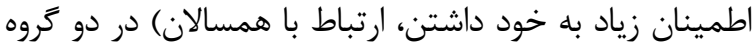

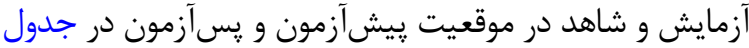
شماره r ارائه شده است.

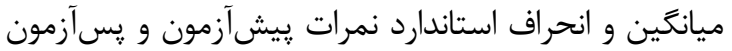

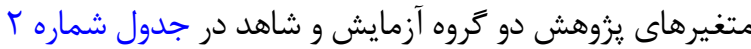

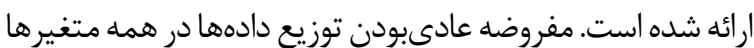

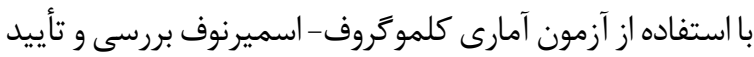

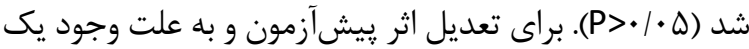

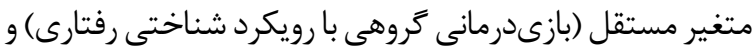

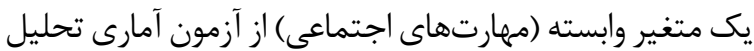

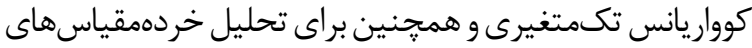

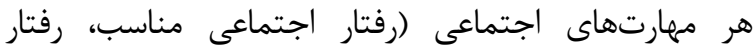

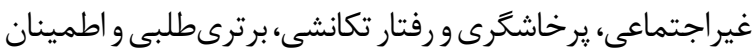

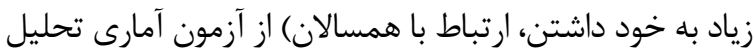
كوواريانس جندمتغيرى استفاده شد.

براى تعيين تأثير بازىدرمانى گروهى با رويكرد شناختى

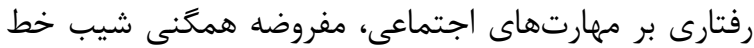

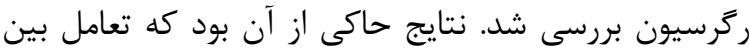

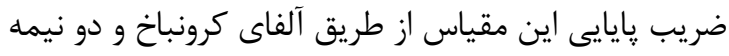

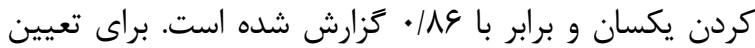

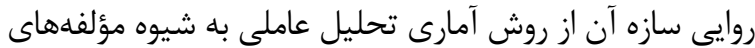

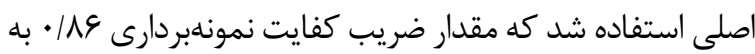

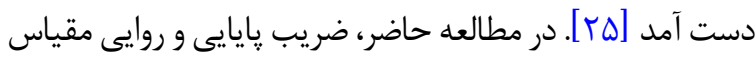

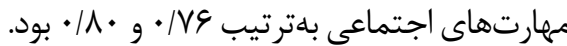
در اولين مرحله يزوهش مقياس مهارتهاى اجتماعى رئى

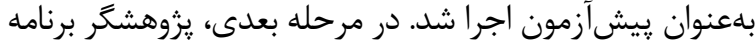

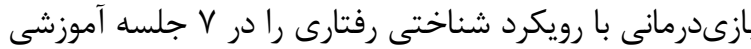

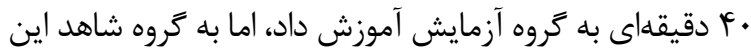

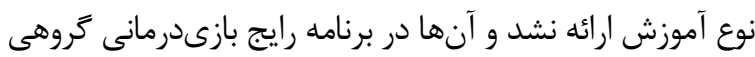

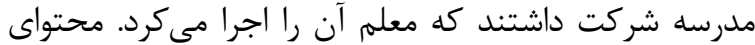

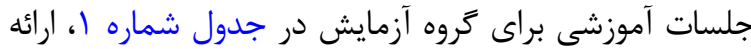

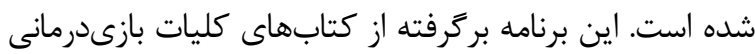

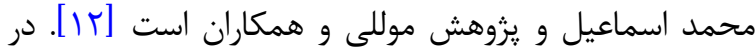

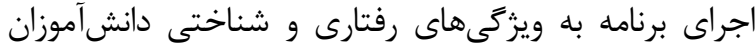

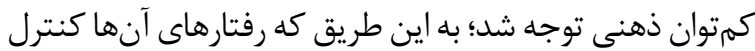

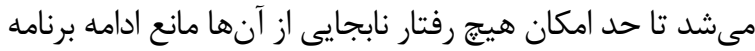

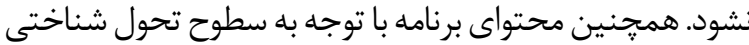

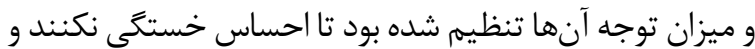

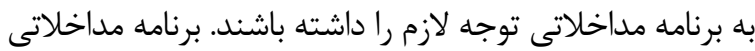

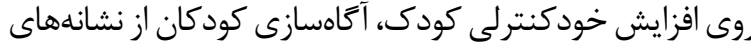

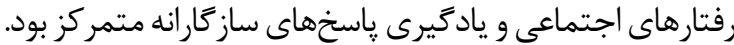

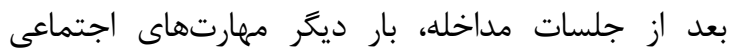

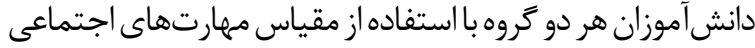

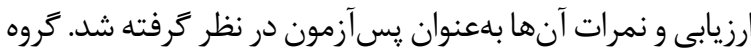

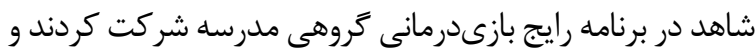

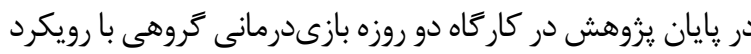

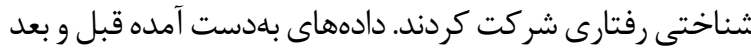

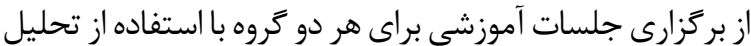


جدول r. ميانگين و انحراف معيار مشكلات رفتارى و مهارتهاى اجتماعى گروه آزمايش و شاهد

\begin{tabular}{|c|c|c|c|c|c|}
\hline \multicolumn{2}{|c|}{ كروه شاهد } & \multicolumn{2}{|c|}{ كَروه آزمايش } & \multirow{2}{*}{ موقعيت } & \multirow{2}{*}{ متغيرها } \\
\hline انحراف معيار & ميانكين & انحراف معيار & ميانكَين & & \\
\hline $1 / \pi r$ & $r \cdot / r^{r}$ & $1 / .9$ & אז/וץ & ييش آزمون & \\
\hline$r / \cdot V$ & $\mathrm{r} / \Delta F$ & $1 / \Delta \Lambda$ & $F T / \Delta S$ & يِ آزمون & \\
\hline $1 / \Gamma 1$ & $r \varphi / r$ & $1 / \Delta T$ & & ييش آزمون & \\
\hline $1 / \cdot v$ & TF/QT & $1 / \Delta V$ & $M F / . \Delta$ & پِسآزمون & \\
\hline $1 / r q$ & TD/Tr & $1 / \cdot r$ & TD/TS & ييش آزمون & \\
\hline $1 / \Delta r$ & $r g / \mu r$ & $1 /$. & $M+/ r$ & يسآزمون & يرخاشحَرى و رفتار تكانشى \\
\hline$\cdot / \mathrm{W}$ & V/rg &.$/ 91$ & $N / v 9$ & ييش آزمون & \\
\hline .199 & $N \cdot r$ & זואו & $\mid F / 11$ & پِ آزمون & برترى طلبى و اطمينان به خود \\
\hline ./AV & $\mid V / 11$ &.$/ 99$ & $\mid V / \cdot{ }^{c}$ & ييش آزمون & 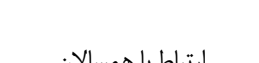 \\
\hline $1 / \Delta F$ & IV/NE & 1/\%ם & $T r / \Delta V$ & پِ آزمون & ק \\
\hline$r / 9 V$ & $1.5 / .9$ & $r / 19$ & $1 \cdot \Delta / F^{c}$ & يِيشآزمون & \\
\hline$r / A F$ & $1 \cdot N / 91$ & $T / T r$ & $\mid \mp V / \Delta$. & يس آزمون & \\
\hline
\end{tabular}

برترىطلبى و اطمينان زياد به خود داشتن، ارتباط با همسالان)،

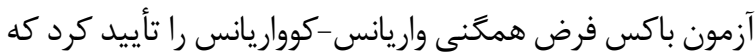

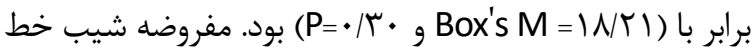
ركرسيون براى متغيرها و خطى بودن رابطه متغيرها برقرار بود. آزمون كرويت بارتلت حاكى از وجود همبستخى كافى بين

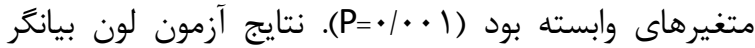

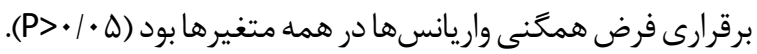

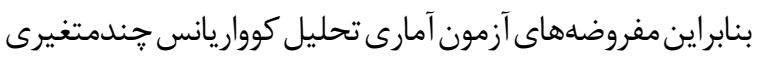

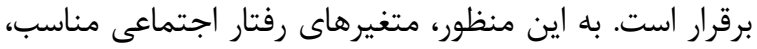

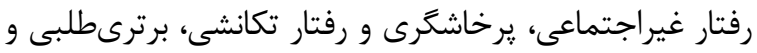

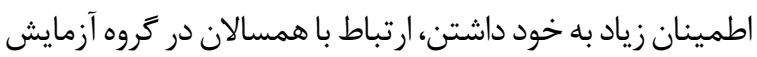

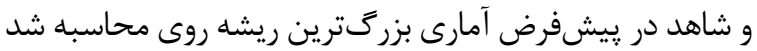

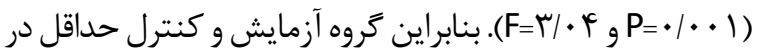

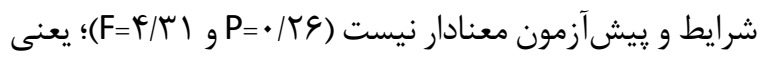

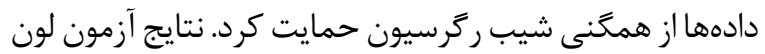

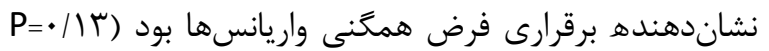

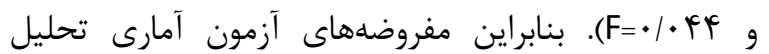

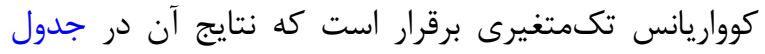
شماره ب ارائه شده است. تُميرى با توجه به نتايج جدول شماره ّ، برنامه مداخلاتى بازى درمانى

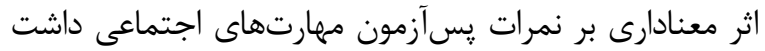

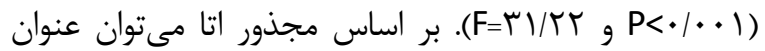

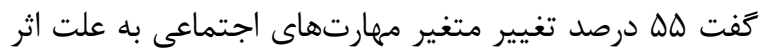
مداخله است. براى تعيين تأثير بازىدرمانى گروهى دئ با رويكرد

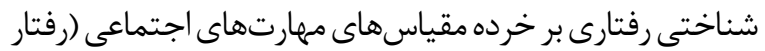

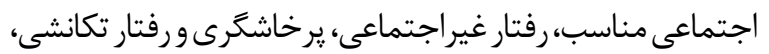

جدول س. نتايج تحليل كوواريانس تكمتغيرى نمره پِآزمون مهارتهاى اجتماعى

\begin{tabular}{|c|c|c|c|c|c|c|c|}
\hline توان آمارى & مجذور اتا & سطح معنادارى & نسبت F & ميانكَين مجذورات & درجه آزادى & مجموع مجذورات & منابع تغيير \\
\hline$\cdot / \mathrm{VA}$ & $.1 \cdot 0$ & . & $r / 1$. & $g r / 4$. & 1 & $g / / 4$. & ييش آزمون \\
\hline \multirow[t]{3}{*}{$\cdot / 199$} & $\cdot / \Delta \Delta$ &.$/ .+1$ & TI/Tr & grv/.9 & 1 & srV/.9 & 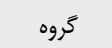 \\
\hline & & & & $r \cdot 1 \cdot 1$ & 19 & $\lceil\Lambda \mid / \Delta \Delta$ & خطا \\
\hline & & & & & r) & $\| T V / \Delta V$ & كل \\
\hline
\end{tabular}

توانبخننى 
جدول ع. نتايج تفكيكى تحليل كوواريانس جند متغيرى براى خرده مقياسهاى مهارتهاى اجتماعى

\begin{tabular}{|c|c|c|c|c|c|c|}
\hline \multicolumn{7}{|c|}{ منابع تغيير } \\
\hline مجذور اتا & سطح معنادارى & 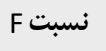 & ميانكَين مجذورات & درجه آزادى & مجموع مجذورات & متغير هاى وابسته \\
\hline$\cdot 19 V$ & $\cdot 1 \cdot \cdot 1$ & $1 N / V Y$ & QGN/IT & 1 & QGN/IT & رفتار اجتماعى مناسب \\
\hline$\cdot / \Delta \Delta$ & $.1 \cdot .1$ & $11 / 4$ & rTD/GY & 1 & tra/gr & رفتار غيراجتماعى \\
\hline$\cdot|9|$ & $.1 \cdot .1$ & $14 / 09$ & $r \cdot N / 9 r$ & 1 & $r \cdot N / 9 T$ & يرخاشَّى و رفتار تكانشى \\
\hline$\cdot 109$ & $.1 \cdot \cdot 1$ & $\mid T / T \Lambda$ & rQV/IV & 1 & rqV/IV & برترى طلبى و اطمينان زياد به خود \\
\hline .194 & $.1 . .1$ & $\mid \Delta / \psi \wedge$ & f. . $/ q r$ & 1 & $f \cdot \cdot \mid q r$ & ارتباط با همسالان \\
\hline
\end{tabular}

توانبخننى

و بهبود مهارتهاى اجتماعى دانشآموزان دختر $\wedge$ تا هاساله

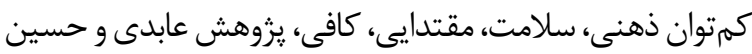

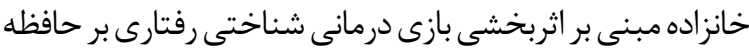

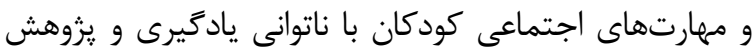

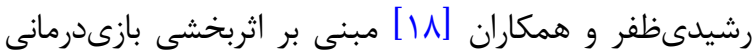

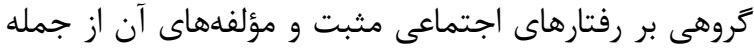

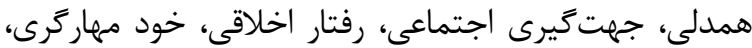

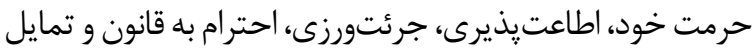

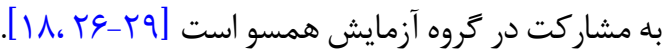
علاوهبر اين، با نتايج مطالعه موللى و همكاران مبنى بر اثربخشى إنى إنى

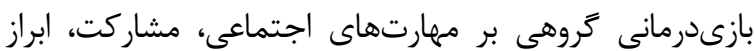

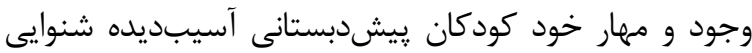

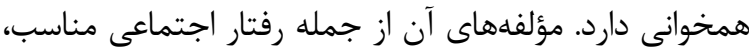

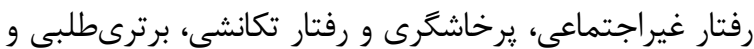

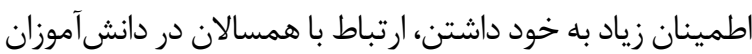

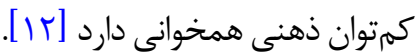
در تبيين اين يافته مى توان كفت اكر جه نتايج يزوهش حاضر

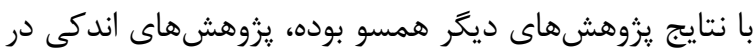

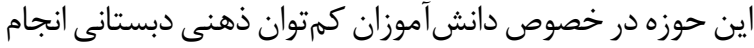

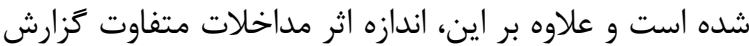

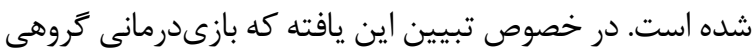

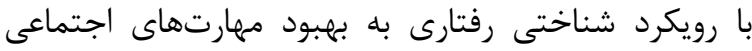

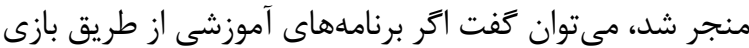

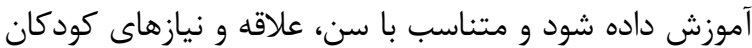

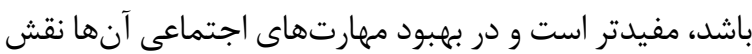

مؤثرترى خواهد داشت [• [ب]. ازطرفديخر، بازىدرمانى گروهى با رويكرد شناختى رفتارى

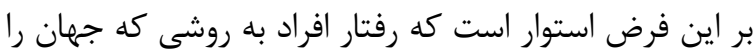

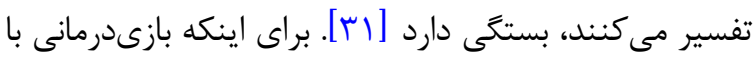

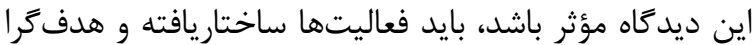

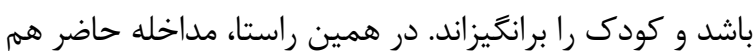

يكى از متغيرها تفاوت معنادارى دارند. به منظور بيىبردن به اين

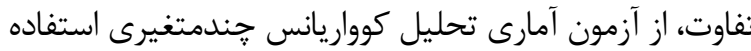

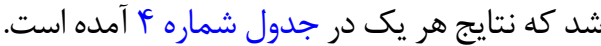

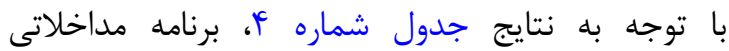

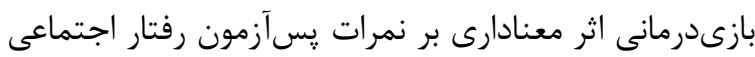

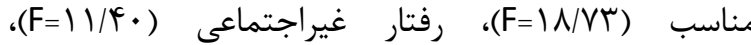

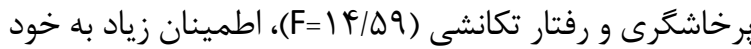

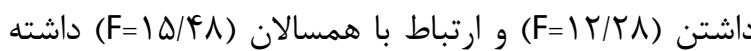

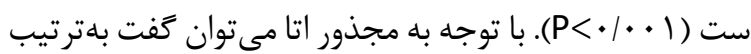

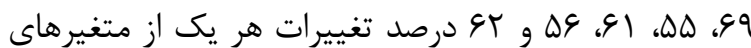

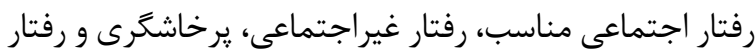

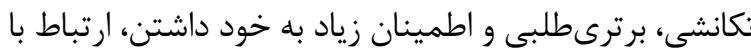

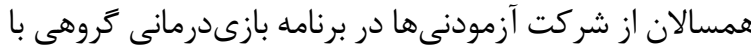

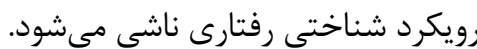

بحث

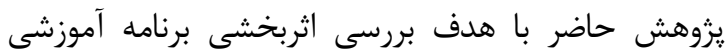

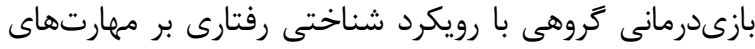

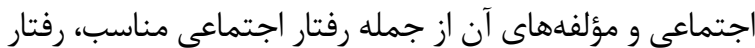

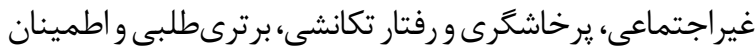

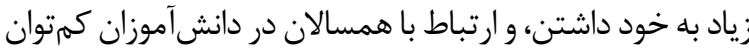

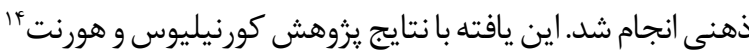

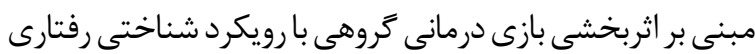

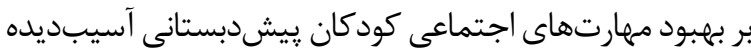

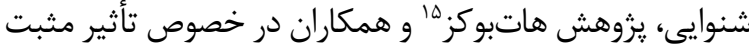

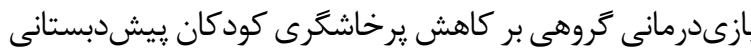

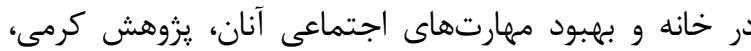

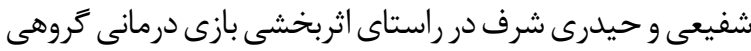

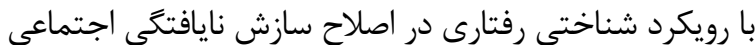

14. Cornelius and Hornett

15. Huth-Bocks 


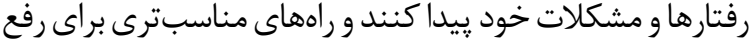

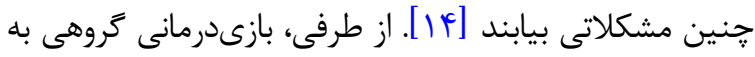

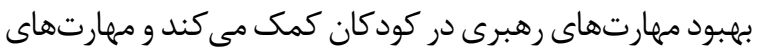

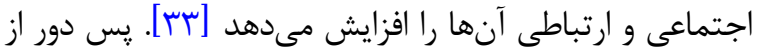
انتظار نيست كه ارتباط با همسالان در دانشآئن آموزان كمتوان

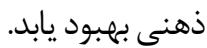

\section{تئيجه كيرى}

نتايج يزوهش حاضر نشان داد آموزش بازىدرمانى كروهى

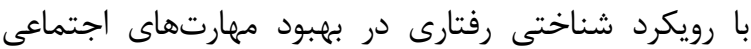

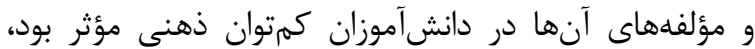

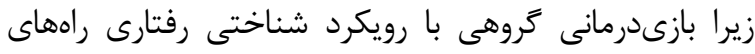

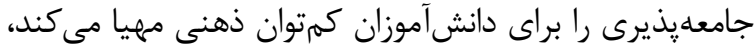

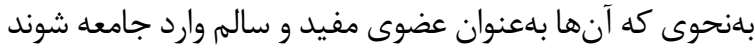

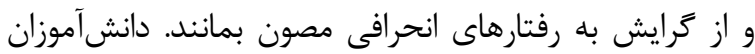

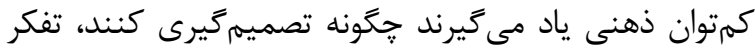

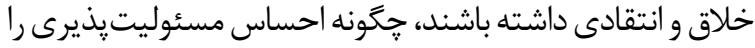

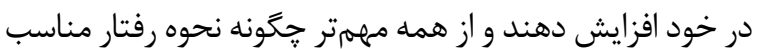

با همسالان را ياد بخيرند [ع] دهن.

علاومبراين، بخش عمدهاى از مشكلات دانشآموزان كمتوان

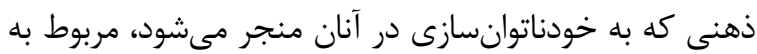

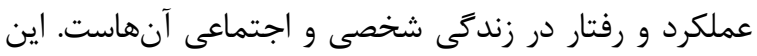

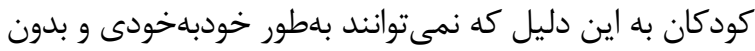

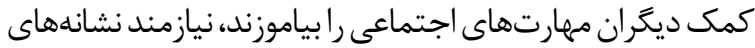

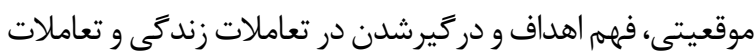

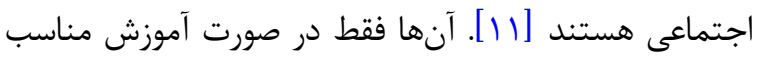

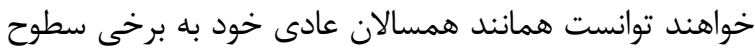

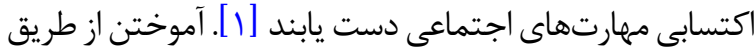

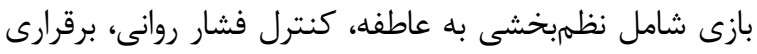

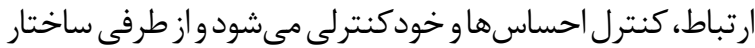

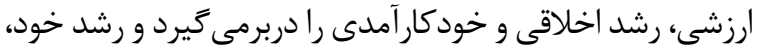

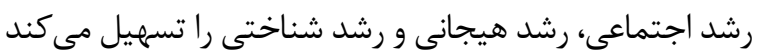

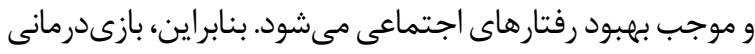

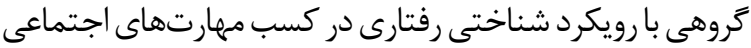
دانش آموزان كمتوان ذهنى نقشى حساس و مهمى دارئ دارد

در يزوهش حاضر محدوديتهايى وجود داشت. از جمله

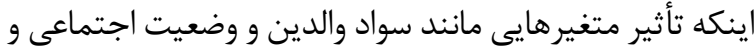

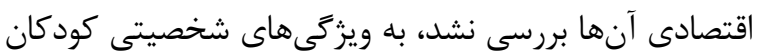

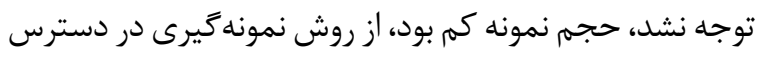

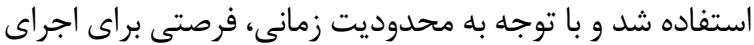

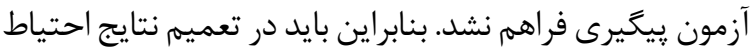

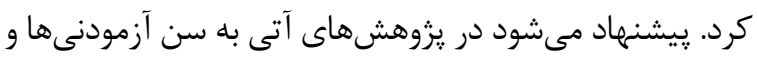
ويزگكى هاى شخصيتى آنها توجه شود، سواد والدين و وضعيت آنهيت

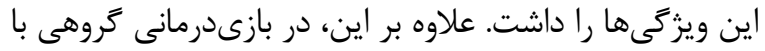

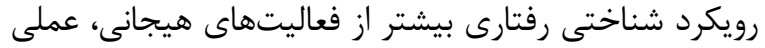

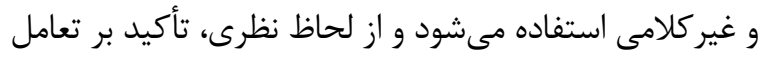

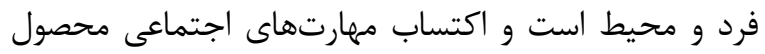

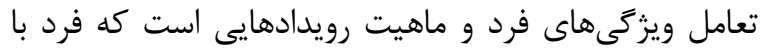

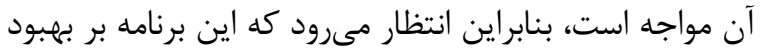

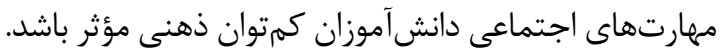

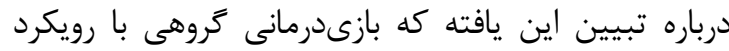

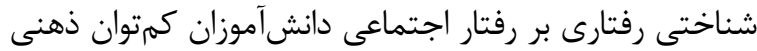

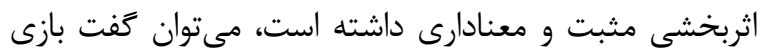

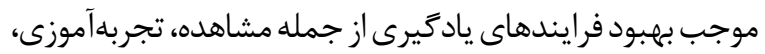

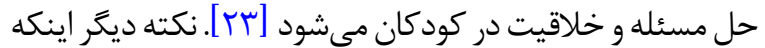

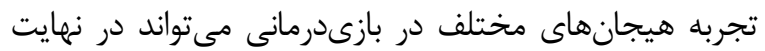

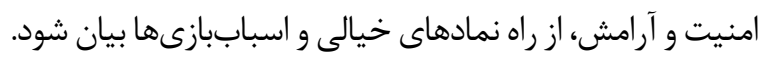

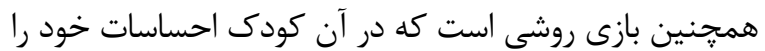

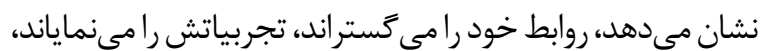

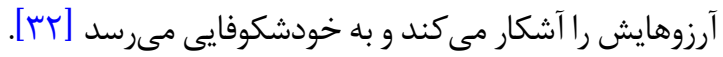

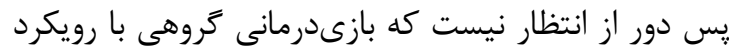

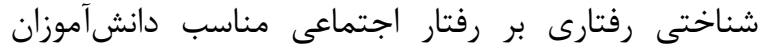

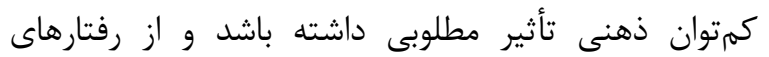

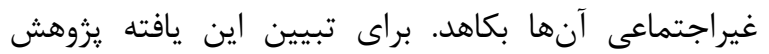

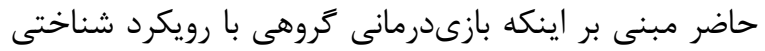

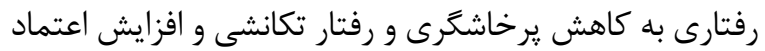

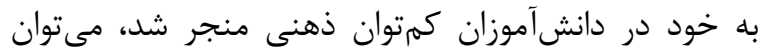

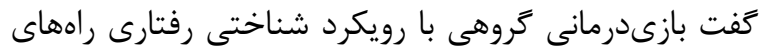

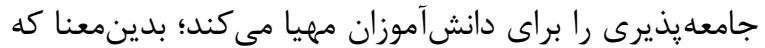

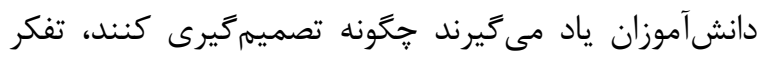

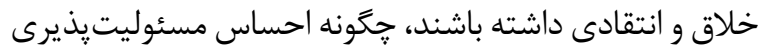

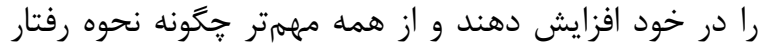

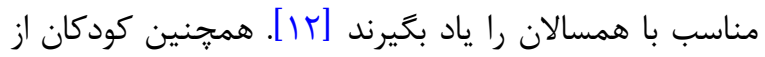

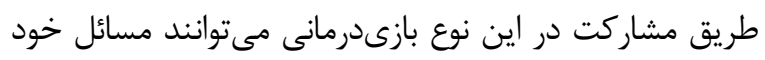

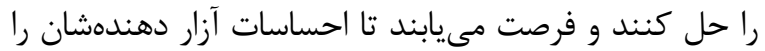

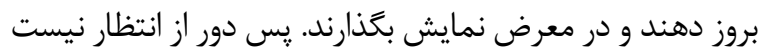

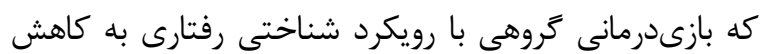

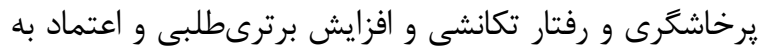

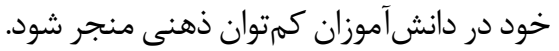
در راستاى تبيين آخرين يافته مبنى بر اين كه بازى إدرمانى

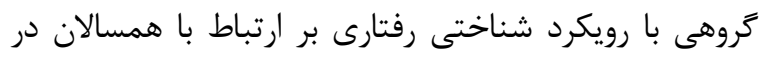

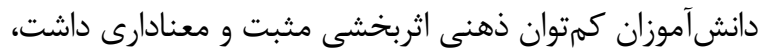

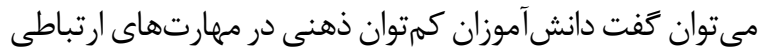

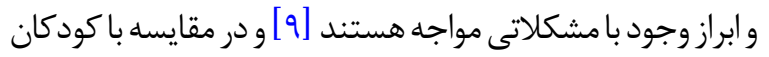

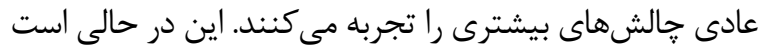

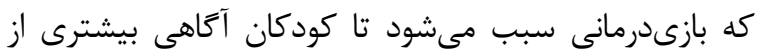


اجتماعى و اقتصادى آنها مدنظر قرار كَيرد، يزوهشهاى آتى بـ آنى

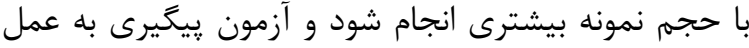

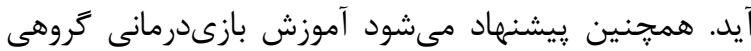

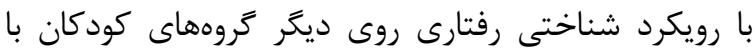

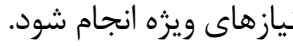

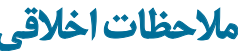

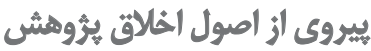

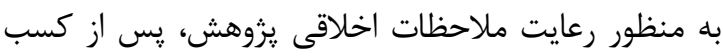

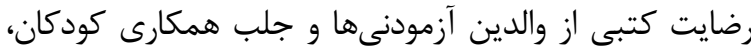

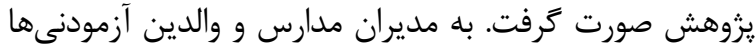

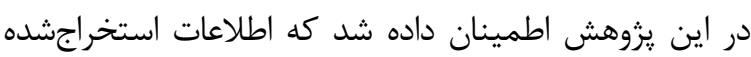

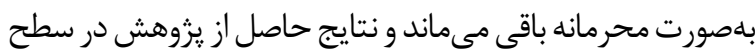

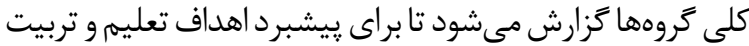

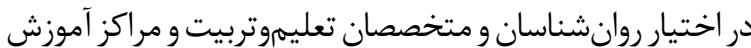
كودكان كمتوان ذهنى قرار كيرد.

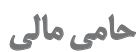

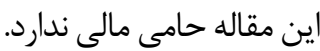

تعارض منافع

بنابر اظهار نويسندكان اين مقاله تعارض منافع ندارد.

$$
\text { تشكر و قدروائى }
$$

بدينوسيله از دانشاموزان كمتوان ذهنى كه در اين يروهش

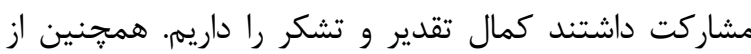

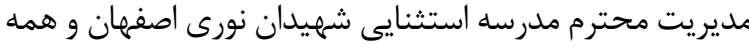

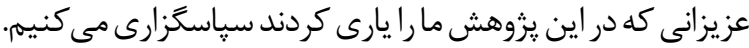




\section{References}

[1] Hallahan DP, Kauffman JM, Pullen PC. Exceptional learners: An introduction to special education. London: Pearson; 2015.

[2] Ashori M, Jalil-Abkenar SS, Ashouri j, Abdollahzade rafi M, Hassanzade M. [Students with special needs and inclusive education (Persian)]. Tehran: Publication of Roshd Farhang; 2016.

[3] Ashori M, Jalil-Abkenar SS, Razavi F. [Definition developmental intelligent disability and its different in diagnostic and statistical manual of mental disorders, 4th and 5th revision (Persian)]. Exceptional Education. 2016; 8(136):57-60

[4] Harris JC. New terminology for mental retardation in DSM-5 and ICD-11. Current Opinion in Psychiatry. 2013; 26(3):260-272. [DOI:10.1097/YCO.0b013e32835fd6fb] [PMID]

[5] Behroz-Sarcheshmeh S, Karimi M, Mahmoudi F, Shaghaghi P, Jalil-Abkenar SS. Effect of training of life skills on social skills of high school students with intellectual disabilities. Practice in Clinical Psychology. 2017; 5(3):177-186. DOI:10.18869/acadpub.jpcp.5.3.177]

[6] Jalil-Abkenar SS, Ashouri M, Afrouz GA. [The effect of social behaviors training on improvement of the social skills of adolescents with intellectual disability (Persian)]. Archives of Rehabilitation. $2013 ; 14(3): 31-40$

[7] O’Handley RD, Radley KC, Lum, JDK. Promoting social communication in a child with specific language impairment. Communication Disorders Quarterly. 2015. 37(4):199-210. [DOI:10.1177/1525740115595346]

[8] Bahrami B, Dolatshahi B, Pourshahbaz A, Mohammadkhani P. Parenting style and emotion regulation in mothers of preschool children. Practice in Clinical Psychology. 2018; 6(1):3-8. [DOI:10.29252/nirp.jpcp.6.1.3]

[9] Harris L, McGarty AM, Hilgenkamp T, Mitchell F, Melville CA. Correlates of objectively measured sedentary time in adults with intellectual disabilities. Preventive Medicine Reports. 2018; 9:1217. [DOI:10.1016/j.pmedr.2017.11.010] [PMID] [PMCID]

[10] Esbjørn BH, Normann N, Christiansen BM, Reinholdt-Dunne ML. The efficacy of group Metacognitive Therapy for Children (MCT-c) with generalized anxiety disorder: An open trial. Journal of Anxiety Disorders. 2018; 53:16-21. [DOI:10.1016/j. janxdis.2017.11.002] [PMID]

[11] Kirk S, Gallagher G, Coleman MR. Educating exceptional children. Boston: Cengage Learning; 2015.

[12] Movallali G, Jalil-Abkenar SS, Ashouri M. [The efficacy of group play therapy on the social skills of pre-school hearing-impaired children (Persian)]. Archives of Rehabilitation. 2015; 16(1):76-85.

[13] Jayne KM, Ray DC. Child-centered play therapy as a comprehensive school counseling approach: directions for research and practice. Person-Centered \& Experiential Psychotherapies. 2016; 15(1):5-18. [DOI:10.1080/14779757.2015.1132757]

[14] Movallali G, Tayebi ramin Z, Rezaee madani M. [Effectiveness of group logo therapy on increasing the quality of the mothers' life of hearing impaired children (Persian)]. Social Welfare. 2016; $16(61): 221-242$
[15] Jindal-Snape D. Vettraino E. Drama techniques for the enhancement of social-emotional development in people with specia needs: review of research. International Journal of Special Education. 2007; 22(1):107-117.

[16] Hoshina AHR., Giannopulu I, Sugaya M. Measurement of the effect of digital play therapy using biological information. Procedia Computer Science. 2017; 112:1570-79. [DOI:10.1016/j. procs.2017.08.104]

[17] Landreth GL, Ray DC, Bratton SC. Play therapy in elementary schools. Psychology in the Schools. 2009; 46(3):281-89. [DOI:10.1002/pits.20374]

[18] Rashidi-Zafar M, Janbozorgi M, Shaghaghi F. [Positive social behavior efficacy of play therapy on progress of pre-school children's (Persian)]. Journal of Behavioral Sciences. 2012; 6(1):69-77.

[19] Favadeddini M, Bidakhti M. [Effect of behavior-based drama therapy on mental retarded females (Persian)]. Journal of Rehabilitation Sciences and Research. 2012; 8(5):913-18.

[20] Astramovich RL, Lyons C, Hamilton NJ. Play therapy for children with intellectual disabilities. Journal of Child and Adolescent Counseling. 2015; 1(1):27-36. [DOI:10.1080/23727810.2 015.1015904]

[21] Bana Sh, Sajedi F, Mirzaie H, Rezasoltani P. The efficacy of cognitive behavioral play therapy on self esteem of children with intellectual disability. Iranian Rehabilitation Journal. 2017; 15(3):235-42. [DOI:10.29252/nrip.irj.15.3.235]

[22] Akbari B, Rahmati F. [The efficacy of cognitive behavioral play therapy on the reduction of aggression in preschool children with attention-deficit/hyperactivity disorder (Persian)]. Quarterly Journal of Child Mental Health. 2015; 2(2):93-100.

[23] Ghodousi N, Sajedi F, Mirzaie H, Rezasoltani P. The effectiveness of cognitive-behavioral play therapy on externalizing behavior problems among street and working children. Iranian Rehabilitation Journal. 2017; 15(4):359-66. [DOI:10.29252/nrip. irj.15.4.359]

[24] Rafati F, Pourmohamadreza-Tajrishi M, Pishyareh E, Mirzaei H Biglarian A. [Effectiveness of group play therapy on the communication of 5-8 years old children with high functioning autism (Persian)]. Archives of Rehabilitation. 2016; 17(3):200-11. [DOI:10.21859/jrehab-1703200]

[25] Yosefi F, Kheir M. [Investigation of reliability and validity of the scale of social skills assessment of Matson and comparision performance of boys and girls in this scale (Persian)]. Journal of Social Sienence of Shiraz University. 2003; 18(2):147-58.

[26] Cornelius G, Hornett D. The play behavior of hearing-impaired kindergarten children. American Annals of the Deaf. 1990; 135(4):316-21. [DOI:10.1353/aad.2012.0542] [PMID]

[27] Huth-Bocks A, Schettini A, Shebroe V. Group play therapy for preschoolers exposed to domestic violence. Journal of Child and Adolescent Group Therapy. 2001; 11(1):19-34. [DOI:10.1023/A:1016693726180]

[28] Karami J, Shafeei B, Heidarisharaf P. [Effectiveness of cognitive-behavioral play therapy on reforming the social maladjustment of female students with intellectual disabilities (Persian)]. Journal of Exceptional Education. 2015; 3(131):21-30. 
[29] Salamat M, Moghtadaei K, Kafbaf M, Abedi AR, Hosein khanzadeh A. [The effectiveness of cognitivebehavioral play therapy on memory and social skills of children with spelling learning disability (Persian)]. Journal of Research Behavioural Sciences. 2014; 11(6):556-566.

[30] Barnes TN, Wang F, O’Brien KM. A meta-analytic review of social problem-solving interventions: Past findings, current status, and future directions. Review of Educational Research. 2016; 87(1):71-102.

[31] Janatian S, Nouri A, Shafti A, Molavi H, Samavatyan H. [Effectiveness of play therapy on the bases of cognitive behavior approach on severity of symptoms of Attention Deficit/Hyperactivity Disorder (ADHD) Among primary school male students aged 9-11(Persian)]. Journal of Research in Behavioural Sciences. 2008; 6(2):109-16.

[32] Azarnioshan B, Beh-Pajooh A, Ghobary Bonab B. [The effectiveness of cognitive behavior-based play therapy on the behavioral problems among primary students with intellectual disabilities(Persian)]. Journal of Exceptional Children. 2012; 12(2):5-16.

[33] Chinekesh A, Kamalian M, Eltemasi M, Chinekesh S, Alavi $\mathrm{M}$. The effect of group play therapy on social-emotional skills in pre-school children. Global Journal of Health Science. 2014; 6(2):163-67. [DOI: 10.5539/gjhs.v6n2p163.] [PMID] [PMCID] 
